\title{
Leituras e escritas de si e do outro: a sala de aula como ambiente multicultural
}

\author{
Lecturas y escrituras de sí y del otro: el aula como ambiente \\ multicultural \\ Readings and writings of self and others: the classroom as a \\ multicultural environment
}

\author{
Dra. Alessandra Fontes Carvalho da Rocha ${ }^{1}$
}

\begin{abstract}
Resumo
O presente trabalho busca discutir as decorrentes consequências da invasão de atitudes e opiniões leigas e do olhar "voyerísta" e massificado em relação às diferentes culturas que se relacionam, particularmente, nas salas de aula e em outros espaços escolares. Procurei analisar como o trabalho com a literatura e outras artes poderia servir para ajudar o homem a falar do homem - de si e do outro. Explicitei algumas possibilidades de prática docente que estimulam a construção de narrativas a partir da leitura contextualizada de textos pré-selecionados que dessem conta de dados culturais, a fim de promover a alteridade no ambiente escolar. O ponto central de minha preocupação está voltado para as possibilidades de articular o material selecionado para o trabalho feito em sala de aula com a perspectiva do pensamento antropológico junto à prática docente, pretendendo ajudar a delimitar materiais que contribuam para a alteridade e, por decorrência, o conhecimento dos elementos culturais e sociais de diferentes grupos humanos, e aplicá-lo ao trabalho do educador não só com os alunos, mas com si próprio, ajudando-o a desnaturalizar olhares e desvelar a polifonia existente nos espaços escolares.
\end{abstract}

Palavras-Chave: Leituras; Escritas; Sala de Aula; Multiculturalismo; Práticas Pedagógicas.

\section{Resumen}

El presente trabajo busca discutir las consecuencias derivadas de la invasión de actitudes y opiniones laicas y de la mirada "voyerísta" y masificado en relación a las diferentes culturas que se relacionan, particularmente, en las aulas y en otros espacios escolares. Buscamos ver cómo el trabajo con la literatura y otras artes podría servir para ayudar al hombre a hablar del hombre - de sí y del otro. Explico algunas posibilidades de práctica docente que estimulan la construcción de narrativas a partir de la lectura contextualizada de textos preseleccionados que dieran cuenta de datos culturales, a fin de promover la alteridad en el ambiente escolar. El punto central de mi preocupación está orientado a las posibilidades de articular el material seleccionado para el trabajo realizado en el aula con la perspectiva del pensamiento antropológico junto a la práctica docente, pretendiendo ayudar a delimitar materiales que contribuyan a la alteridad y, por consiguiente, el conocimiento de los elementos culturales y sociales de diferentes grupos humanos, y aplicarlo al trabajo del educador no sólo con los alumnos, sino con sí mismo, ayudándolo a desnaturalizar las miradas y desvelar la polifonía existente en los espacios escolares.

Palabras claves: lecturas; escrita; Clase; Multiculturalismo; Prácticas Pedagógicas

\section{Abstract}

\footnotetext{
${ }^{1}$ Doutora em Estudos de Literatura; Universidade Federal do Rio de Janeiro - UFRJ; Rio de Janeiro, Rio de Janeiro, Brasil; profa.alessandra.fontes@gmail.com
} 
This paper seeks to discuss the consequences derived from the invasion of secular attitudes and opinions and from the "voyerist" and mass view in relation to the different cultures that are related, particularly in the classrooms and in other school spaces. I seek to see how working with literature and other arts could serve to help man talk about man - of himself and of the other. I explain some possibilities of teaching practice that stimulate the construction of narratives from the contextualized reading of preselected texts that account for cultural data, in order to promote otherness in the school environment. The central of my concern is oriented to the possibilities of articulating the material selected for the work done in the classroom with the perspective of anthropological thinking together with the teaching practice, trying to help delimit materials that contribute to the otherness and, consequently, the knowledge of the cultural and social elements of different human groups, and apply it to the work of the educator not only with the students, but with himself, helping him to denaturalize the looks and reveal the polyphony existing in the school spaces

\section{Introdução}

O ponto central de minha preocupação está voltado para as possibilidades de articular a construção de imagens fotográficas com a perspectiva do pensamento antropológico junto à prática docente. Nestre trabalho, pretendi ajudar a delimitar um campo específico que denomina-se fotoetnografia, uma forma específica de fotografia informada pelo saber antropológico e, por decorrência, empenhada no inventário dos elementos culturais e sociais de grupos humanos, e aplicá-lo ao trabalho do educador não só com os estudantes, mas com si próprio, ajudando-o a desnaturalizar olhares e desvelar a polifonia existente nos espaços escolares.

Aqui, trato das questões implicadas no ato de olhar: como este é social e tecnicamente determinado, assim como diversas formas do olhar e as modificações ocorridas quando do surgimento da fotografia. Busco também registrar a urgência de uma fase de reeducação do olhar que ocorre devido ao desenvolvimento de um "novo mundo" virtual em que estamos todos implicados. Já que é em função do tipo de olhar de uma dada época e de um determinado contexto que são determinados os tipos de imagens e a forma como as pessoas se relacionam com elas. Por uma abordagem descritiva, onde a principal forma de narrar é o uso de uma determinada imagem escolhida, busquei investigar os elementos através dos quais uma população de estudantes da educação básica e moradores de zonas urbanas do município do Rio de Janeiro constroem narrações de uma identidade baseadas na sua própria. Que definição e que tipo de apropriação esta população faz da foto apresentada a eles, sem que seja dito o significado da imagem. Em outras palavras, como esta população dentro de uma cultura urbanizada concebe a imagem que lhe é apresentada, sem saber que se trata da foto de um espantalho (foto apresentada para o trabalho).

A partir do uso da fotografia, busquei pensar e desenvolver uma modalidade da antropologia visual como uma linguagem e um olhar, capaz de, no processo de conhecer, nos apresentar dados e informações, nos levar a uma reflexão a cerca do nosso próprio olhar, 
mostrando os aspectos inacessíveis ao olhar "leigo", porém naturalizado a esta limitação e construído pelos padrões culturais nos quais estamos inseridos.

O ponto de partida para a reflexão que se pretende aqui empreender é dado pelo pensamento de Roland Barthes. Pelo que ele chama de "Paradoxo Fotográfico", tratarei a fotografia dentro deste duplo modo de ver. A maneira objetiva da denotação e a função subjetiva dada ao leitor, ou melhor dizendo, a "mensagem contínua" (ou análogo do real) e a "mensagem suplementar" (ou seu estilo).

Assim, o convite inicial deste trabalho será para que o leitor pense sobre algumas conceituações implicadas no estudo da imagem fixa, como a fotografia; conscientize-se da naturalização do olhar e reflita sobre esta naturalização e suas conseqüências em sala de aula. E ainda uma questão que entendo como norteadora deste trabalho: como estas conceituações dialogam com a Educação, e como esta pode interferir na desnaturalização do olhar.

\section{Breves considerações acerca da fotografia: mensagem fotográfica de Roland Barthes}

Segundo Barthes (1984, p. 127-129, grifo do autor),

A fotografia não fala (forçosamente) daquilo que não é mais, mas apenas e com certeza daquilo que foi. [...] A essência da fotografia consiste em ratificar o que ela representa. [...] Ela não inventa; é a própria autenticação [...], é um certificado de presença.

Assim, nos nossos dias, a imagem fotográfica, digitalizada ou transformada por técnicas de computação, herdou o status de "certificado de presença", de atestado da realidade, induzindo também à credibilidade incontestada. Mas, a fotografia já não mais pode ser considerada a realidade. Um bom leitor de imagem, ao vê-la, pode ver a vida que está ali representada. O registro carrega sempre esse caráter de memória, com a questão cultural. E o que é o registro? Ele sai da linguagem, não é a realidade vivida, já é a realidade interpretada. É uma leitura do real. Como é o homem histórico que tira a fotografia, o registro traz essa marca.

Sendo assim, é possível afirmar que tanto as imagens "fabricadas" como os simples registros passam a ter a mesma força e representam escolhas feitas, textos com seus discursos apropriados. Para cada uma dessas escolhas temos muitas não-escolhas, ou melhor, discursos silenciados. Sob esse prisma, “a fotografia não é só pseudopresença, mas também símbolo de ausência” (SONTAG, 1983, P.16). O “poderia ser” ou o "poderá vir a ser" passa a ser aceito. Mesmo estando longe do objeto fotografado, pode-se sentir sua presença e perceber este 
objeto como único, como privilegiado, podendo ser guardado e revisto em qualquer momento da vida. E, novamente relembrando Bergson (1990), revivemos o momento fotografado através da "memória involuntária"

Em relação à não transparência deste tipo de texto, Sontag (1983, p.22) afirma: “a fotografia, na verdade, é incapaz de explicar o que quer que seja, é um convite inexaurível à dedução, à especulação e à fantasia". Ela nos toca, de alguma maneira e nos leva a várias interpretações. Entram em jogo, neste momento, nossos sentimentos, gostos, saberes e vivências. O que agrada a uns, desagrada a outros.

\begin{abstract}
Decidi então tomar como guia de minha nova análise a atração que sentia por certas fotos. Pois pelo menos dessa atração eu estava certo. Como chamá-la? Fascinação? Não, tal fotografia que destaco e de que gosto não tem nada do ponto brilhante que balança diante dos olhos e que faz a cabeça oscilar; o que ela produz em mim é exatamente o contrário do estupor; antes uma agitação interior, uma festa, um trabalho também, a pressão do indizível que quer se dizer. Então? Interesse? Isso é insuficiente; não tenho necessidade de interrogar minha comoção para enumerar as diferentes razões que temos para nos interessarmos por uma foto; podemos: seja desejar o objeto, a paisagem, o corpo que ela representa; seja amar ou ser amado o ser que ela nos dá a reconhecer; seja espantarmo-nos com o que vemos; seja admirar ou discutir o desempenho do fotógrafo etc [...] Tal foto pode satisfazer a um deles e me interessar pouco; e se tal outra me interessa muito, eu gostaria de saber o que, nessa foto, me dá o estalo (BARTHES, 1984, p.35-36).
\end{abstract}

Assim, Barthes escolhe a palavra "aventura" para nomear essa atração. Segundo ele, a foto surge, de repente, ele a anima e é animado por ela, como numa verdadeira "animação". A foto não é em nada animada, mas ela o anima, como num sentimento produzido por toda aventura. E não necessitamos de explicação para definirmos sentimentos. Sentimos, gostamos ou não e nada mais interessa.

Foi esse mesmo sentimento de atração que uma foto apresentada em uma aula de Língua Portuguesa para turma do sétimo ano de uma escola pública da cidade do Rio de Janeiro despertou o interesse sobre questões referentes ao olhar do outro e ao fato de aplicá-lo à educação. Em um dos momentos da aula sobre um texto que envolvia multiculturalismo, a professora $^{2}$ mostrou uma foto aos estudantes e perguntou o que eles poderiam falar sobre a imagem contida no fotografia.

Muitos foram os palpites. Alguns respondiam: _ "É um ritual. Parece “macumba”!!”. Uma outra estudante narrou o que poderia ter acontecido antes do objeto ser fotografado: “Ah! Isso aí foi um "bebum” que passou e deixou as garrafas penduradas." Um outro aluno complementou: _ "Acho que depois de um churrasco, todo mundo ficou doidão e aí deu

\footnotetext{
${ }^{2}$ Professora Alessandra Fontes Carvalho da Rocha.
} 
nisso." Uma outra aluna ficou mais sensibilizada e relatou: _ "Com certeza alguém morreu nesse local. A cruz seria uma espécie de símbolo que marca o local da morte. Já as garrafas... pode ter sido o tal "bebum" que passou e deixou por ali."

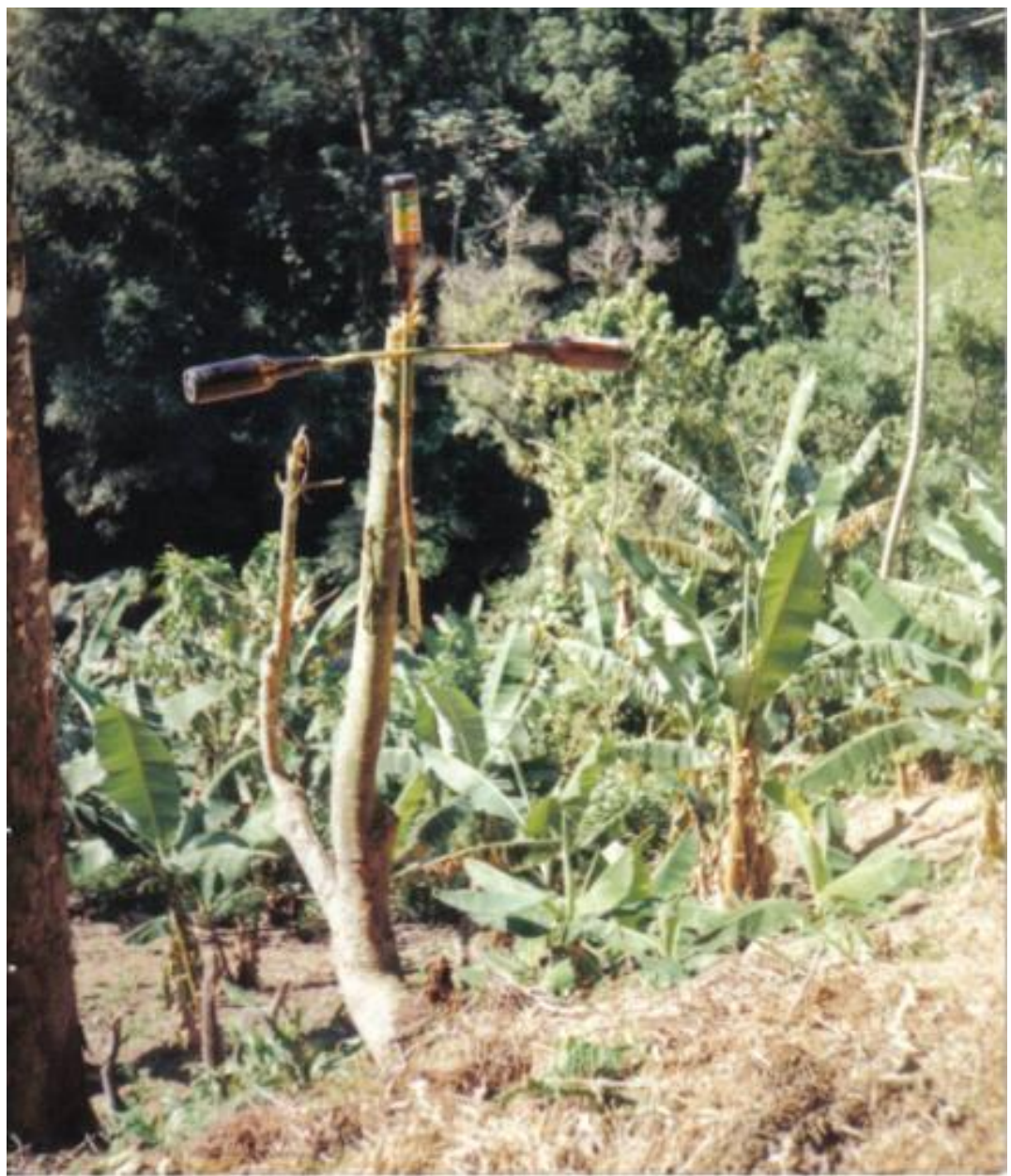

Imagem 1 - Fotografia apresentada pela professora Alessandra Fontes à turma de estudantes do sétimo ano. Registro fotográfico feito em Raiz da Serra (Saracuruna), em 1994. Fonte: Acervo pessoal.

Quando a professora revelou para a turma que a resposta da estudante significava exatamente o que a foto representava: aquela cruz com três garrafas em cada ponta era um espantalho, todos os outros estudantes riram com um ar de estranhamento, pois o espantalho fotografado está bem longe da concepção de espantalho de muitos dos presentes na sala de aula - espantalhos que aparecem em desenhos animados, feitos de palha, e que são sempre bem simpáticos. Os estudantes traziam referências muito próximas aos dos espantalhos apresentados por desenhos e filmes produzidos pela Walt Disney Pictures.

O interesse pela foto e a reflexão e análise dos discursos apresentados durante a aula me fizeram ampliar tais questões levando-as para outros espaços da instituição escolar que abrigam discursos carregados de julgamentos de valores e (pré)conceitos que pode fadar um aluno ao caminho do fracasso, além de nos conduzir a um conjunto de inquietações acerca de 
como narramos aos/os outros, de como os outros se narram, e de como essas narrações são, finalmente, colocadas de um modo estático nas práticas pedagógicas, ou seja, a polifonia existente nas relações interpessoais.

O que gostaria de aqui salientar é que outras questões se levantam agora em termos de uma teoria crítica do olhar e da escuta nas práticas docentes. A Escola e seus atores não podem silenciar as vozes que lhe pareçam dissonantes do discurso culturalmente padronizado, uma vez que não opera no vazio. Não vale a pena pretender unificá-la de maneira abstrata e formal, quando ela se realiza num mundo profundamente diverso. E por isso, penso que os que ensinam terão que ter consciência de que os que aprendem são, tal como eles próprios, seres sociais portadores de um mundo muito especial de crenças, significados, valores, atitudes e comportamentos construídos a partir das relações com a família, comunidade, etc e que importa contemplar.

\section{O campo da educação: desnaturalizando o olhar}

As preocupações na área da educação têm levado à busca de contribuições em outros campos científicos para ampliar as possibilidades de análise dos objetos, o que tem contribuído em muito na forma de analisar a escola e as questões que a cercam. Um exemplo concreto disso é a utilização da etnografia na educação, ou seja, buscamos na antropologia referenciais para nossas análises dos fenômenos educacionais.

Um dos princípios básicos da etnografia se traduz na seguinte questão: a centralidade do conceito de cultura na etnografia. A antropologia está fortemente vinculada à noção de cultura. E a educação mantém relação íntima com a cultura, assim como nos diz Forquin:

Quer se tome a palavra 'educação' no sentido amplo, de formação e socialização do indivíduo, quer se restrinja ao domínio escolar, é necessário reconhecer que, se toda educação é sempre educação de alguém por alguém, ela supõe sempre a comunicação, a transmissão, a aquisição de alguma coisa: conhecimentos, competências, crenças, hábitos, valores, que constituem o que se chama precisamente de 'conteúdo' da educação. Devido ao fato de que este conteúdo parece irredutível ao que há de particular e de contingente na experiência subjetiva ou intersubjetiva imediata, constituindo, antes, a moldura, o suporte e a forma de toda experiência individual possível, devido, então, a que este conteúdo que se transmite na educação é sempre alguma coisa que nos precede, nos ultrapasse e nos institui enquanto sujeitos humanos, pode-se perfeitamente dar-lhe o nome de cultura. (FORQUIN, 1993, p. 10)

Reflexões a respeito da relação entre educação e cultura acabam na conclusão de que é de grande responsabilidade da escola a transmissão e a perpetuação da experiência humana que nada mais é que cultura. Assim, Forquin afirma que "a cultura é o conteúdo substancial 
da educação (...): a educação não é nada fora da cultura e sem ela.”(FORQUIN, 1993, p. 10) Mas, ele alerta que a educação não transmite a cultura, ou uma cultura ou culturas. Ela transmite algo da cultura, elementos de cultura.

A vinculação educação/cultura não se limita apenas à esfera da transmissão cultural. Para compreender os processos e práticas pedagógicas, seja o professor ou o pesquisador, necessitam estar permanentemente atentos ao fato de que alunos de meios sociais diferentes chegam à escola com características culturais determinadas que influenciam de forma direta na maneira como respondem às solicitações e exigências próprias da escolarização. Além disso, esta compreensão do processo supõe a consideração das características culturais dos próprios professores, seus saberes, seus valores, seus referenciais. E, por fim, não é possível negar a contribuição que o conceito de cultura traz para o entendimento da escola.

Da mesma forma que a vinculação entre educação/cultura e antropologia/cultura é reconhecida, reconhece-se, também, a vinculação educação/antropologia estabelecida pela cultura. Com base no reconhecimento entre antropologia e educação, mediada pela cultura, há a possibilidade da utilização da etnografia, identificada como a prática do antropólogo para interpretar a cultura na investigação dos processos e práticas educativas. A utilização da etnografia na investigação dos fenômenos educacionais requer o olhar antropológico por parte do pesquisador ou do próprio professor. E o importante ao olhar antropológico não é apenas o reconhecimento e registro da diversidade cultural, mas também a busca do significado de tais comportamentos: são experiências humanas de sociabilidade, de trabalho, de entretenimento que só aparecem como exóticas, estranhas, ou até mesmo perigosas quando seu significado é desconhecido.

Se por um lado, a relação entre educação e cultura torna a etnografia uma forma interessante para interpretar o fenômeno educativo, por outro, pode trazer o problema do “olhar" ofuscado do pesquisador ou professor. Este problema só é superado pelo entendimento da relativização. O princípio da relativização consiste no descentramento da sociedade do observador, colocando o eixo de referência no universo investigado. Isto significa que o investigador, por um "olhar" relativizador, busca as significações do outro, admite lógicas diferentes das suas de entender, conceber e recriar o mundo e ultrapassar seus próprios valores, ou seja, o olhar etnocêntrico é abandonado.

Assim, verificam-se, nas escolas ${ }^{3}$, grupos distintos. De um lado, os professores com seus padrões culturais das suas classes que são coincidentes com os da escola, e, de outro, os

\footnotetext{
${ }^{3}$ Tem-se como referência as escolas públicas da cidade do Rio de Janeiro.
} 
alunos provenientes das classes populares, mantendo relações de conflito muitas vezes por sua cultura ser tão distinta e distante das dos espaços escolares. Por isso, muito do fracasso dos alunos é justificado por estes estarem à margem da cultura dos dominantes, e, portanto, privados da cultura. Mas o olhar relativizador mostrará o aluno não mais pela 'ótica da privação cultural', buscando entendê-lo na positividade de seu universo cultural e não restrito a indicadores de sua privação, face à lógica social do seu próprio grupo.

No âmbito da pesquisa, o pesquisador enfrentará como parte da tradição desse sistema de referências, o desafio de construir um conhecimento fruto da relativização. Este é um conhecimento do 'outro' nos seus próprios termos, a partir do seu ponto de vista, das suas categorias de pensamento, bem como de sua lógica e, portanto, de seus sistemas de representação e classificação, assim como vimos nas falas dos estudantes referente à fotografia do espantalho em uma platação de bananeiras apresentada em sala de aula.

Os olhares relativizadores do professor e do pesquisador lhes permitem um conhecimento mais aproximado da verdade sobre o aluno e sua cultura, compreendida como um trabalho de campo livre de pressupostos e juízo de valores. Está aí a riqueza da antropologia no campo educacional. As etnografias não devem ser análises definitivas, fechadas, amarradas por uma teoria geral de cultura determinista. Devem, isto, sim, ser alvo de reanálises. O olhar antropológico se faz importante para o pesquisador da área educacional porque é com ele e por meio dele que as dificuldades serão superadas, assim como para o trabalho do professor em sala de aula.

Portanto, concretizando-se a aliança da educação com a antropologia, significa que se faz necessário: considerar a escola como espaço social e terreno cultural onde se criam e recriam conhecimentos, valores, significados e onde ocorrem movimentos de acomodação, de contestação e de resistência. Esta é uma prática enriquecedora para o pesquisador como também para o professor, que com uma abordagem antropológica, conhece o seu aluno com outras lentes. Em outras palavras, analisando a heterogeneidade e adversidade sócio cultural na qual cada indivíduo está inserido, abandona uma postura etnocêntrica que faz do "diferente" um inferior e da diferença uma "privação cultural".

\section{Novos recortes que devem anteceder o julgamento, o juízo de valor, ...}

Como escolhi um suporte e gêneros relacionados à linguagem visual: a fotoetnografia, resolvi fazer um recorte para estudá-la com mais cuidado. Linguagem visual, base da mídia 
moderna. Imagem fixa ou em movimento de jornais, revistas, livros, televisão, cinema e computador, Internet. Imagem fotográfica, pictórica, colorida, artística ou não - imagem texto. Imagens, em geral - parte integrante da cultura e do ambiente no mundo pós-moderno. Crianças, jovens, adultos estão em constante contato com elas, por meio de cartazes, outdoors, desenhos, livros de histórias, televisão, vídeo, cinema, desenho animado e videogames, bem antes mesmo de saberem ler.

As imagens exercem um fascínio enorme, sendo ao mesmo tempo fonte de prazer, de distração, de sofrimentos, de angústia e de tantos outros sentimentos em função do que suscitam em nós. O impacto dessa linguagem se apóia na sua carga emocional. Apesar da sedução que exercem e da aparente facilidade de acesso, de compreensão e leitura, as imagens nem sempre são transparentes e imediatamente descritíveis. Essa leitura também precisa ser aprendida e muitas vezes estimulada, descoberta.

É necessário verificar e acompanhar, estar atento a este consumo imagético, fazendo comentários, apreciações ou aconselhando. Isto evita confusões entre imaginário e real, entre ficção e realidade. Em geral, algumas famílias de nível sociocultural mais elevado fazem um pouco esta parte, mas o mesmo não acontece com todas as crianças. Cabe, então, à escola este papel de sensibilizar as crianças para esta questão da relação com as imagens, ajudá-las na aproximação de tais materiais para que possam ter discernimento suficiente e apreciá-las, sendo curiosas e criticas ao mesmo tempo sem perder o prazer pela imagem.

Cada vez mais se comprova a necessidade do uso da imagem em sala de aula. E aí que impera as imagens presentes na fotoetnografia. Este tipo de texto, não tão presente no nosso dia a dia, pode levar a trabalhos bem interessantes com objetivos que completam perfeitamente o ensino/aprendizagem e evidenciam toda uma polifonia presente nas salas de aula que, na moiaria das vezes, é anulada.

O professor tem um papel fundamental nesse trabalho. Ele precisa chamar a atenção do aluno para que perceba o que está por trás das mensagens presentes nas imagens. Ao fazer isso, estará argumentando e mostrando seus pontos de vista e, querendo ou não, estará manipulando esse público, os seus ouvintes para que aceitem a sua visão dos fatos.

O que é importante é que tanto professores quanto alunos estejam conscientes da necessidade de se discutir, relativizando as questões, de examinar um assunto sob vários prismas, enfim, de valorizar os vários ângulos de uma determinada imagem, para que nenhuma das partes se sinta subjugada pela outra. 
Exatamente o mesmo acontece com o texto verbal escrito. Temos até o exemplo de uma escritora e professora francesa, Cécile Ladjali (2005, p. 25), que, ao ser entrevistada pela Revista Le Monde de l'Education, declarou:

\begin{abstract}
O livro que se coloca nas mãos de uma criança é um livro de que a gente gosta. A leitura que se faz desta obra mostra a nossa visão de mundo. A subjetividade faz parte integrante de uma aula [...] Tenho consciência de manipula-los [os alunos]. Mas será que isso é um problema? Um mal? Longe de querer apagar sua personalidade, tento acentua-la, confrontando-a com a alteridade. Eles lêem, escrevem, [...] ficam felizes. Experimentam, com vontade, a novidade. Eles se constroem.
\end{abstract}

Nesta fase escolar, em geral, as primeiras escolhas, aquelas que são feitas antes das aulas, do material que será levado para as turmas, pertencem ao professor. Cabe a ele, educador, propor e direcionar os trabalhos. Sendo assim, como ele lidera as atividades, é natural que sua opinião, de certo modo, fale mais alto e influencie o educando, mesmo que essa não seja sua intenção. Quando o professor faz uma apreciação, ele passa seu ponto de vista; sua visão de mundo. Mas tudo isso pode ser feito de maneira respeitosa, levando em conta, também, o olhar do aluno. E o aluno, ao comparar sua opinião com a do professor, ao ver o outro, ele se vê, se constrói.

Retomando o texto imagético, no caso as imagens pertencentes ao que chamamos de fotoetnografia, procuramos explorar a paixão que os jovens têm pela imagem, não afastá-la, mas utilizá-la como nossa aliada, principalmente na escola, com fins pedagógicos, como, por exemplo, através de um trabalho de reflexão, de análise, assim como através do desenvolvimento da observação, do olhar, dos sentidos e das percepções, de maneira geral, como o trabalho realizado com a foto do espantalho.

Quanto ao direcionamento do olhar, é importante dizer que a visão não é o único sentido atingido pela imagem. O corpo inteiro se envolve na experiência. Sua linguagem é dinâmica e envolvente, porque há um apelo à emoção. $\mathrm{O}$ que os alunos experimentam, ao aprenderem a ler esse tipo de linguagem, é precisamente a capacidade da observação, que leva a um direcionamento do olhar, da consciência e da liberdade. A construção de uma consciência crítica face a esse tipo de leitura corresponde, certamente, a uma necessidade social de primeira urgência, pois condiciona, de modo importante, sua relação com a coletividade e cidadania.

Estamos cercados pela linguagem (imagética e tantas outras) e imersos nela; por ela passaram todas as formas de inserção e de relação com o mundo. Todas as coisas existem numa relação com o tempo, espaço e pessoa. Por exemplo, uma música que ouvimos pode nos 
remeter à visualização de imagens representativas de cenas, objetos ou situações vivenciadas por nós, num determinado espaço, remetendo-nos a um determinado tempo.

Em relação a isso, o filósofo Henri Bergson, em seu livro Matéria e Memória, afirma que o passado sobrevive em mecanismos motores ou em lembranças independentes. Considerando-se cada uma dessas memórias em estado puro, teríamos, segundo ele, a "memória voluntária" (consciente) e a "memória involuntária", espontânea (inconsciente). A primeira é também chamada por muitos de memória-hábito, "é um automatismo psíquico que adquirimos pela repetição contínua de alguma coisa, como, por exemplo, quando aprendemos alguma coisa de cor” (CHAUI, 1999, p. 129). É baseada na repetição. É mais motora e ativa, de cunho mais utilitário. Lançamos mão dela ao dirigirmos um carro, quando freamos diante de um sinal vermelho, por exemplo, ao tomarmos atitudes mais mecânicas e repetitivas, ao fazermos passos de determinada dança, quando lidamos com computadores ou mesmo quando nos lembramos de fatos ocorridos na véspera, num passado próximo ou mesmo em um passado mais distante. Basta iniciar um movimento, uma palavra, um gesto para que venha à tona toda a série de automatismos necessários. Trata-se de uma memória impessoal, já que

A lembrança aprendida sairá do tempo à medida que a lição for melhor sabida; tornarse-á cada vez mais impessoal, cada vez mais estranha à nossa vida passada. [...] A repetição [...] tem por resultado [...] utilizar cada vez mais os movimentos [...], organizar esses movimentos entre si e, montando um mecanismo, criar um hábito do corpo (BERGSON, 1999, p. 64).

Todos esses movimentos "involuntários" são realizados por nós praticamente sem que pensemos neles, são quase automáticos. É desse automatismo que o trabalho com a fotoetnografia distancia-se, consistindo em levar o aluno a considerar a imagem de maneira reflexiva e crítica, interagindo com a sua ideologia, confrontando-a com a sua própria (do aluno), ou transformando-a. Bergson continua dizendo que esse automatismo

só é lembrança porque me lembro de tê-lo adquirido; e só me lembro de tê-lo adquirido porque apelo à memória espontânea, aquela que data os acontecimentos e só os registra uma vez. [...] Para recuperar o passado em forma de imagem, é preciso poder abstrair-se da ação presente, é preciso saber dar valor ao inútil, é preciso querer sonhar (Ibid., p. 63-64).

Dependendo da situação, ao ouvirmos uma certa música; ao saborearmos um determinado alimento; ao observarmos uma foto, podemos fazer surgir do mais profundo de 
nosso inconsciente lembranças e sabores de nosso passado, que nos trarão de volta imagens desse passado com toda a força, cor e presença no tempo.

E várias linguagens participam dessas imagens pretéritas e revividas. Temos então um "passeio" constante entre elas, fazendo com que se interprenetrem, se unam, se completem. Mas isso só é possível pelo desenvolvimento da sensibilidade, do trabalho com a estética

ligada ao sensível. É importante reconhecer a força que esses recursos representam para o ensino das várias disciplinas, com um triplo objetivo de transmitir a nossos alunos e a nós mesmos, educadores, um saber-fazer e um saber-viver indispensáveis à nossa sociedade, onde impera o discurso dominante e a homogeneidade.

\section{Considerações Finais}

A todo momento a educação permeará toda a rede social e relações possíveis dentro e fora da mesma, o que nos obriga a ter uma reflexão crítica sobre o que é o educar e de que forma este ato está tão ligado ao conceito de cultura. Com esse entendimento, é possível realizar uma reflexão mais crítica acerca dos temas naturalização e desnaturalização do olhar, cultura e fotoetnografia, até mesmo pelos próprios professores e estudantes da área de educação.

Uma melhor compreensão crítica sobre o que é educar/viver para todos que são educadores, para todos aqueles que estão abertos ao diálogo, não faria mal a nenhum deles e faria o melhor pelos educandos, atentando sempre para sabermos ouvir o outro, aprender o valor do silêncio para o observador e romper com alguns conceitos já cristalizados, buscando uma atitude de "estranhamento" do que nos parece mais familiar, pensando em outros sistemas de referência que não o nosso próprio (assim como aconteceu com a análise da fotografia apresentada em uma turma de sétimo ano), outras formas de representar, definir, classificar, organizar a realidade e o cotidiano, que não em nossos próprios termos, aos quais já estamos mais do que habituados, ou seja, temos a oportunidade de ultrapassar estereótipos e buscar explicar a diferença e a especificidade de um determinado universo social pela abordagem etnográfica.

Assim, em um curso de formação de professores, por exemplo, se torna cada vez mais importante tratar da naturalização do olhar, a fim de quebrar com esta cristalização. A fotografia e todo o discurso em torno dela são importantes para visualizarmos a permanência 
de uma cegueira cultural entre os cidadãos. Atribuímos ao nosso olhar somente a nossa vivência, nossa bagagem cultural. É a partir da cultura de cada um que são construídos os significados e os rótulos para tudo que não faz parte da nossa cultura.

Deste modo, o problema de pensar o aluno dotado de uma identidade construída histórica e socialmente ainda permanece, e só com uma formação visando o olhar antropológico (uma observação etnográfica) é que futuramente na prática, nós - futuros educadores -, iremos dar importância não só ao cotidiano do discente, mas também à história, sabendo respeitar a diferença cultural e a heterogeneidade de experiências sociais.

\section{Referências}

BARTHES, Roland. A Câmara Clara. Edições 70, Lisboa, 1980. . Elementos de semiologia. Lisboa: Edições 70, 1981. O óbvio e o obtuso. Lisboa: Edições 70, 1984. . A Mensagem Fotográfica. Teoria de Cultura de Massas, Adordo et al. Luis Costa Lima, org - \#. Ed. Rio de Janeiro, Paz e Terra, 1982. A mensagem fotográfica. Lisboa : Edições 70, 1984. p 13-25. Aula. São Paulo: Cultrix, 2001. 9a edição

BECEYRO, Raúl. Ensayos sobre fotografia. Buenos Aires : Arte y Libros, 1980.

BERGSON, Henri. Matéria e memória: ensaio sobre a relação do corpo com o espírito. Trad. Paulo Neves da Silva. São Paulo: Martins Fontes, 1990.

BOURDIEU, Pierre; CHAMPAGNE, Patrick. Les exclus de l'intérieur. Le Monde de l'Éducation, Paris, n.338, juil./août, 2005.

CHAUÍ, Marilena. Convite à filosofia. São Paulo: Edditora Ática, 1999.

DUBOIS, Philippe. O Ato Fotográfico e outros Ensaios. Papirus, Campinas, 1994.

FORQUIN, Jean Claude. Escola e Cultura: as bases sociais e epistemológicas do conhecimento escolar. Porto Alegre: Artes Médicas Sul, 1993.

LADJALI, Cécile. Rechercher le vertife. Le Monde de l'Éducation, n. 338, Paris, juil./août, 2005.

SONTAG, S. Ensaios Sobre a Fotografia. Rio de Janeiro, Arbor, 1981. 